\title{
Plant Responses to Heat Stress: Physiology, Transcription, Noncoding RNAs, and Epigenetics
}

\author{
Jianguo Zhao ${ }^{1,2,+}$, Zhaogeng Lu ${ }^{1,+}{ }^{,}$Li Wang ${ }^{1}$ and Biao Jin ${ }^{1, *(\mathbb{C})}$ \\ 1 College of Horticulture and Plant Protection, Yangzhou University, Yangzhou 225009, China; \\ zhaojg@yzu.edu.cn (J.Z.); d160068@yzu.edu.cn (Z.L.); liwang@yzu.edu.cn (L.W.) \\ 2 Guangling College of Yangzhou University, Yangzhou University, Yangzhou 225009, China \\ * Correspondence: bjin@yzu.edu.cn \\ + These authors contributed equally to this work.
}

check for

updates

Citation: Zhao, J.; Lu, Z.; Wang, L.; Jin, B. Plant Responses to Heat Stress: Physiology, Transcription, Noncoding RNAs, and Epigenetics. Int. J. Mol. Sci. 2021, 22, 117. https://dx.doi.org/ $10.3390 /$ ijms 22010117

Received: 27 October 2020

Accepted: 20 November 2020

Published: 24 December 2020

Publisher's Note: MDPI stays neutral with regard to jurisdictional claims in published maps and institutional affiliations.

Copyright: $\odot 2020$ by the authors. Licensee MDPI, Basel, Switzerland. This article is an open access article distributed under the terms and conditions of the Creative Commons Attribution (CC BY) license (https:/ / creativecommons.org/ licenses/by/4.0/).

\begin{abstract}
Global warming has increased the frequency of extreme high temperature events. High temperature is a major abiotic stress that limits the growth and production of plants. Therefore, the plant response to heat stress (HS) has been a focus of research. However, the plant response to HS involves complex physiological traits and molecular or gene networks that are not fully understood. Here, we review recent progress in the physiological (photosynthesis, cell membrane thermostability, oxidative damage, and others), transcriptional, and post-transcriptional (noncoding RNAs) regulation of the plant response to HS. We also summarize advances in understanding of the epigenetic regulation (DNA methylation, histone modification, and chromatin remodeling) and epigenetic memory underlying plant-heat interactions. Finally, we discuss the challenges and opportunities of future research in the plant response to HS.
\end{abstract}

Keywords: heat stress; physiological; molecular; non-coding RNA; epigenetics

\section{Introduction}

Plants as sessile organisms cannot move to favorable environments upon encountering abiotic or biotic stresses; consequently, plant growth, development, and productivity are markedly affected [1]. High temperature is an important stress and global warming has accelerated the increase in air temperature in recent decades [2]. Therefore, the mechanisms by which plants respond to high temperature are of great interest. Plants exposed to high temperature (heat stress, HS) suffer from severe, and sometimes lethal, adverse effects. To cope with such conditions, plants have evolved sophisticated mechanisms to respond to HS. For example, several basic physiological processes of plants-including photosynthesis, respiration, and water metabolism - respond to HS [3,4]. Much progress has been made in characterizing HS-responsive genes, non-coding RNAs, DNA methylation, and histone modifications. Here, we focus on the physiological, transcriptional, post-transcriptional, and epigenetic mechanisms underlying the plant HS response.

\section{Physiological Responses of Plants under HS}

A variety of physiological processes-such as photosynthesis, respiration, transpiration, membrane thermostability, and osmotic regulation - are adversely affected by HS. Some common effects of HS on plant physiological responses, growth and development, and yield are shown in Figure 1.

\subsection{Photosynthesis}

Generally, HS reduces photosynthetic efficiency, thus shortening the plant life cycle and diminishing productivity [5]. Photosynthesis is also one of the most heat-sensitive physiological processes. Under HS, photochemical reactions in thylakoid lamellae and carbon metabolism in the stroma of chloroplasts are prone to injury [6,7]. Heat stress 
causes disruption of thylakoid membranes, thereby inhibiting the activities of membraneassociated electron carriers and enzymes, reducing the rate of photosynthesis. Specifically, photosystem II (PSII) activity is greatly reduced or even stops under HS because PSII complex is the most heat-intolerant [6,8]. In addition, HS influences chloroplast structure and the thermal stability of components of the photosynthetic system, reducing ribulose1,5-bisphosphate carboxylase/oxygenase (Rubisco) activity, amounts of photosynthetic pigments, and the carbon fixation capacity $[6,9,10]$. These factors contribute significantly to the reduction of photosynthetic efficiency under HS. Therefore, a fundamental understanding of the response of photosynthetic physiology is helpful to study the thermostability of plants and the adverse effects of warming on crop yield [11].

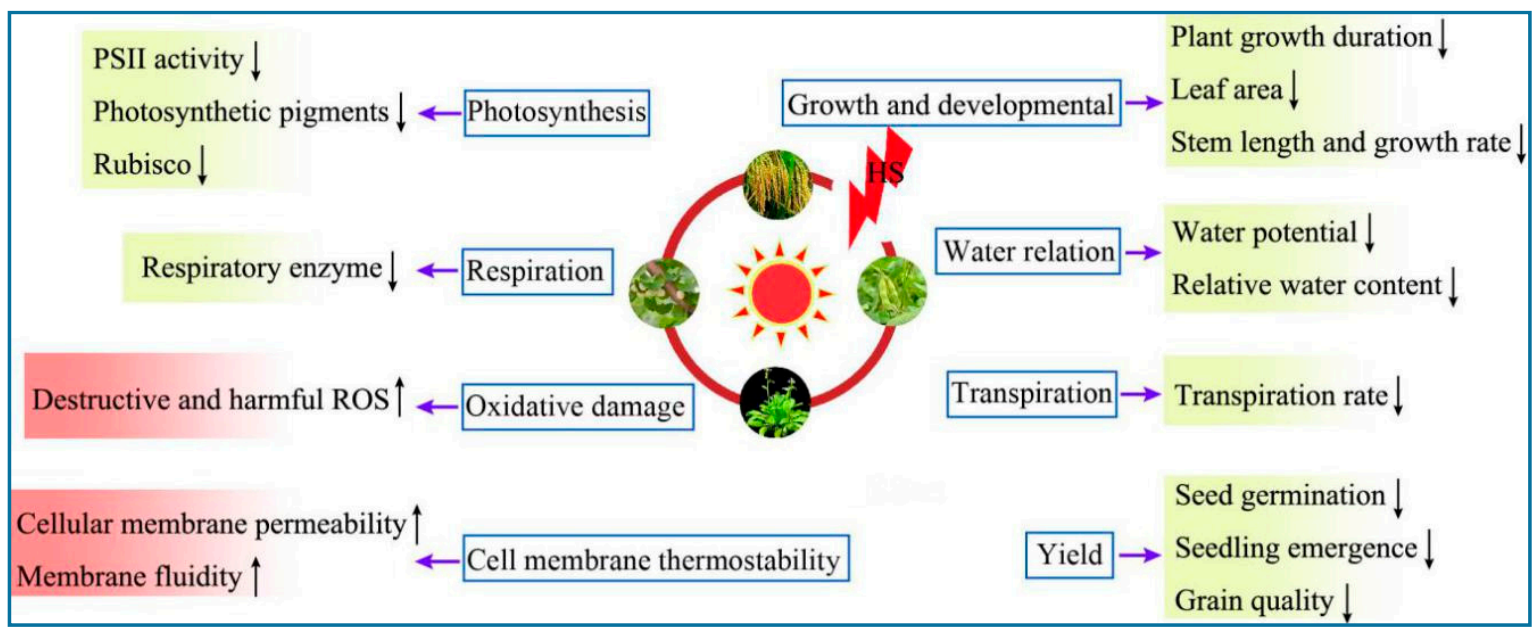

Figure 1. Effects of heat stress on plant physiological responses. Upward-pointing arrows indicate activated/upregulated physiological indices. Downward-pointing arrows indicate deactivated/downregulated physiological indices. Abbreviations: HS, heat stress; PSII, photosystem II; Rubisco, ribulose-1,5-bisphosphate carboxylase/oxygenase; ROS, reactive oxygen species.

\subsection{Cell Membrane Thermostability}

Membrane dysfunction is the main physiological consequence of plant exposure to HS. Under extreme HS, the increased kinetic energy and movement of biomolecules across membranes loosens chemical bonds, leading to disintegration of membrane lipids and increasing membrane fluidity [12]. HS increases cellular membrane permeability and the loss of cellular electrolytes, consequently inhibiting cellular function and decreasing thermotolerance [5]. In addition, the reactive oxygen species (ROS) accumulation caused by HS leads to membrane damage, decreasing thermotolerance [13]. In short, membrane thermostability plays an important role in conferring tolerance to HS in plants.

\subsection{Oxidative Damage}

Plants exposed to HS show accumulation of ROS-singlet oxygen $\left({ }^{1} \mathrm{O}_{2}\right)$, superoxide radical $\left(\mathrm{O}_{2}^{-}\right)$, hydrogen peroxide $\left(\mathrm{H}_{2} \mathrm{O}_{2}\right)$, and hydroxyl radical $\left(\mathrm{OH}^{-}\right)$- generating oxidative stress [14]. The ROS are generated mainly in PSI and PSII. In PSII, excess energy generates the triplet state of chlorophylls, which pass excitation energy to $\mathrm{O}_{2}$, producing singlet oxygen. Over-reduction of PSI leads to generation of the superoxide anion, promoting $\mathrm{H}_{2} \mathrm{O}_{2}$ production [8]. ROS (e.g., $\mathrm{O}_{2}{ }^{-}, \mathrm{H}_{2} \mathrm{O}_{2}$ ) induce oxidative stress by altering membrane properties, degrading proteins, and inactivating enzymes, thus reducing plant cell viability [15]. Heat stress induces lipid peroxidation due to free radical damage of the cell membrane [6]. Under HS, the content of malondialdehyde (MAD; an indicator of lipid peroxidation) is significantly increased in many plants such as sorghum [16]. ROS can also trigger programmed cell death under HS. On the other hand, plants have developed mechanisms to detoxify ROS and enhance heat tolerance. Plants increase their thermotolerance 
by recruiting the antioxidant enzymes superoxide dismutase (SOD), ascorbate peroxidase (APX), catalase (CAT), glutathione reductase (GR), and peroxidase (POX) [17].

\subsection{Other Physiological Responses}

Plant water status is generally erratic under changing temperatures [5]. Heat stress causes dehydration and affects plant growth and development. Water potential and relative water content are substantially decreased upon exposure to HS, reducing photosynthetic productivity [3]. However, under transient or mild HS, plants regulate the rate of respiration and transpiration to balance water loss and heat dissipation. The level of soluble sugars and proteins are also altered during HS to regulate osmotic pressure within the cell [18]. Finally, HS reduces the yield of cultivated crops, including cereals, legumes, and oil crops [19].

\section{Molecular Responses of Plants under HS}

\subsection{Transcriptional Regulation of HS Responses}

When plants are subjected to HS, the expression of a series of heat shock transcription factor (HSF) and heat shock protein (HSP) genes is induced. The HSFs rapidly induce the expression of HSPs, and both HSFs and HSPs play central roles in the plant HS response and induction of thermotolerance [20,21]. However, overexpression of a single HSF or HSP gene has little impact on thermotolerance, suggesting that HSFs and HSPs act synergistically to confer HS resistance.

Plant HSFs are divided into three conserved evolutionary classes (A, B, and C) according to the structural features of their oligomerization domains. Class A HSFs are essential for transcriptional activation. However, Class B and C HSFs have no activator function because they lack the appropriate motif comprising acidic amino acid residues [22]. Among class A HSFs, HSFA1 is the master transcriptional activator, triggering the immediate expression of other HS-responsive transcription factors (TFs) [20], including DEHYDRATIONRESPONSIVE ELEMENT BINDING PROTEIN 2A (DREB2A), HSFA2, HSFA7, HSFBs, and MULTIPROTEIN-BRIDGING FACTOR 1C (MBF1C) (Figure 2). HSFA1 transactivation activity is induced by interaction with HEAT SHOCK PROTEIN 70 (HSP70) and HSP90 under HS [23]. Interestingly, both HSFA1a and HSFA1b are important for the initial phase of HS-responsive gene expression [24]. HSFA2, as a heat-inducible transactivator, prolongs acquired thermotolerance by maintaining the expression of HSP genes in Arabidopsis [25]. HSFA3 is regulated by DREB2A and DREB2C, playing a role in thermotolerance [20,26]. DREB2A, a key transcription factor, directly regulates HSFA3 transcription via a coactivator complex of NUCLEAR FACTOR Y, SUBUNIT A2 (NF-YA2), NF-YB3, and DNA POLYMERASE II SUBUNIT B3-1 (DPB3-1)/NF-YC10 under HS (Figure 2). In addition, HSFA4a and HSFA 8 act as sensors of the ROS produced as secondary stress responses during the HS response in Arabidopsis [27].

Among class B HSFs, HSFBs are transcriptional repressors and negatively regulate the expression of many heat-inducible HSFs (HSFA2, HSFA7s) and HSPS (e.g., HSP101, HSP70). In addition, HSFBs are downstream target genes of HSFA1s in plants, and they influence and interact with each other, forming the regulatory network responsible for the expression of HS-responsive genes (Figure 2), for instance, in Arabidopsis, tomato, and tall fescue (Festuca arundinacea) [23,28,29]. The functions and roles of class C HSFs are unclear. In wheat, overexpression of TaHSFC2a-B resulted in upregulation of HSPs and other heat protection genes (e.g., TaHSP70d and TaGalSyn) and improved thermotolerance. Overexpression of FaHSFC1b (cloned from tall fescue) in Arabidopsis enhanced heat tolerance by inducing or upregulating the expression of HSPs [29]. In addition, HSFC genes are upregulated by HS in wheat [30], cabbage (Brassica rapa) [31], and soybean (Glycine max) [32]. 


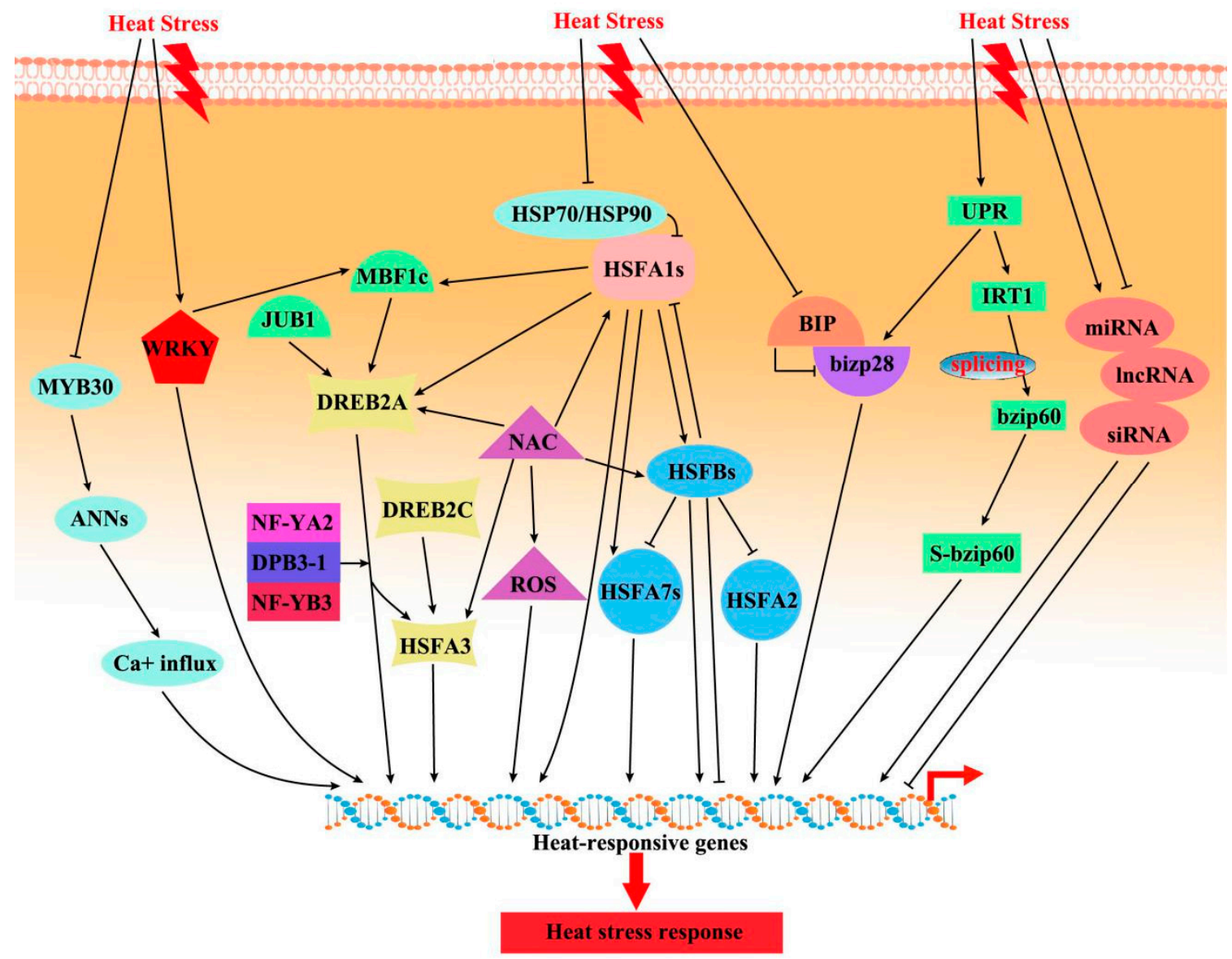

Figure 2. Schematic of the main regulatory pathways that respond to HS transcription factors. The binding of heat shock protein (HSP)70/90 and heat shock transcription factor (HSF)A1s represses the activity of HSFA1s under nonstress conditions, whereas heat stress elicits the dissociation of HSFA1 from HSP70 and HSP90, leading to HSFA1 activation. Abbreviations: HSP, heat shock protein; HSF, heat shock transcription factor; ANN, annexin; JUB1, jungbrunnen 1; MBF1c, multiprotein-bridging factor 1c; DREB2A/2C dehydration-responsive element binding protein 2A/2C; NF-Y, nuclear factor Y; DPB3-1, DNA polymerase II subunit B3-1; ROS, reactive oxygen species; BIP, binding immunoglobulin protein; bIZP, basic leucine zipper; S-bzip60, spliced bZIP60; UPR, unfolded protein response; IRT1, inositol-requiring enzyme 1; miRNA, microRNA; lncRNA, long non-coding RNA; siRNA, small interfering RNA.

Other TF families, such as MBF1C, NAC, WRKY, bZIP (basic leucine zipper), and MYB, are also involved in the regulation of heat-responsive genes (Figure 2). MBF1C is a highly conserved transcriptional coactivator and a key regulator of thermotolerance [33]. Indeed, an mbf1c mutant had reduced the expression levels of DREB2A and HSFBs during HS. In addition, HSFA1s regulate the expression of MBF1C during HS. NACs are one of the largest transcription factor families in plants and are involved in the response to HS. NAC transcription factors bind to the promoters of HSFs (e.g., HSFA1b, HSFA6b, HSFA7a, and HSFC1), increasing their expression and thus enhancing thermotolerance [34,35]. Moreover, TaNAC2L enhanced heat resistance by regulating the expression of HS-response genes (e.g., AtHSFA3, AtDREB2A) in wheat [36] (Figure 2). Interestingly, the overexpression of OsNAC3 in rice enhanced tolerance to HS by modulating ROS homeostasis [37]. The NAC transcription factor JUNGBRUNNEN1 (JUB1) regulates the expression of DREB2A under HS [38].

Notably, a minimal yet significant level of acquired thermotolerance can be attained in plants by induction of the expression of a small number of genes regulated by other transcription factors such as WRKY, bZIP, and MYB. WRKYs participate in developmental and physiological processes, as well as in stress responses. Under HS, WRKY18, WRKY25, WRKY26, WRKY33, WRKY39, WRKY40, WRKY46, and WRKY68 coordinately induce 
plant thermotolerance by positively regulating HSP-related signaling pathways (e.g., HSFs, HSPs, and MBF1c) $[39,40]$. In addition, OsWRKY11 in rice plays a role in the HS response and tolerance. Overexpression of OsWRKY11 under the control of the HSP101 promoter led to enhanced heat tolerance [41].

The bZIP transcription factors and the unfolded protein response (UPR) play important roles in plant thermotolerance. bZIP28 and bZIP60, which localize to the endoplasmic reticulum (ER) membrane, are transferred to the nucleus, where they activate the expression of stress-responsive genes [42]. Under HS, the ER membrane-localized RNA splicing factor IRE1 (INOSITOL-REQUIRING ENZYME 1) splices the mRNA of $b Z I P 60$, causing synthesis of a spliced bZIP60 (sbZIP60), which translocates into the nucleus [28]. The ER-localized chaperone BiP (BINDING PROTEIN) binds to bZIP28 and inhibits its activation under non-stress conditions. The coordination of bZIP28 and HSFA2 is involved in regulation of the HS response in Arabidopsis. bZIP28-deficient plants showed enhanced activation of cytosolic APX-, MBF1c-, HSP-dependent pathways, and had elevated HSFA2 transcript levels, suggesting these pathways compensate for the deficiency in bZIP28 during HS [43]. The activation of bZIP17 is controlled by HS in a manner similar to the regulatory mechanism that controls the UPR. In lily (Lilium longiflorum), promotion of thermotolerance by LlHSFAs involves regulation of bZip factors (AtbZIP11, AtbZIP44) [44]. In addition, the response pathway of bZIPs is activated during prolonged warming [19].

MYBs are involved in plant development, metabolism, and stress responses. MYB30 regulates HS responses via ANNEXIN (ANN)-mediated cytosolic calcium signaling in Arabidopsis [45]. MYB30 binds to the promoters of ANN1 and ANN4 and represses their expression. Subsequently, ANNs modulate heat-induced $\left[\mathrm{Ca}^{2+}\right]_{\mathrm{cyt}}$ elevation, triggering downstream HS responses (Figure 2). In addition, the overexpression in rice of OsMYB55 increased the accumulation of amino acids (e.g., glutamic acid, gamma aminobutyric acid, arginine, and proline), further improving the heat resistance of rice at the vegetative stage [46].

\subsection{Regulation of HS Responses by Non-Coding RNAs}

Although transcription factors are the core regulators of transcription during HS, plant non-coding RNAs (ncRNAs) play an important role in the response to HS (Figure 3). ncRNAs are a class of regulatory RNAs comprising microRNAs (miRNAs), small interfering RNAs (siRNAs), long non-coding RNAs (lncRNAs), and circular RNAs (circRNAs) [47]. ncRNAs play important roles in the HS response by regulating the activity of TF s or genes.

MicroRNAs are a class of small ncRNAs that negatively regulate gene expression by degrading mRNA or inhibiting translation [48]. miR156 isoforms are induced by HS and are important for HS memory. During recovery from HS, miR156 sustains the expression of HS-responsive genes (e.g., HSFA2 and HSPs) via SPLs in Arabidopsis [49]. As a result of conservation of miR156, the miR156-SPL module that regulates HS memory is conserved in plants. By contrast, miR398 is rapidly induced in response to HS, downregulating its target genes (CSD1/2, copper/zinc superoxide dismutase1/2; CCS, copper chaperone for superoxide dismutase) [50]. This leads to ROS accumulation and increased HSF and HSP levels. Given that miR398 expression is under the control of HSFAs, this regulatory mechanism constitutes a positive feedback loop. In addition, miR398 and its target CSDs are implicated in the HS responses of Brassica rapa and Populus tomentosa [51]. miR159 is rapidly induced in wheat exposed to HS [52]. GAMYB TFs, the main targets of miR159, have roles in heat tolerance. Indeed, transgenic wheat overexpressing miR159 and a myb33myb65 Arabidopsis mutant showed increased susceptibility to HS, indicating that miR159 regulates plant heat tolerance by GAMYB targets. miR396 regulates HaWRKY6 during early responses to HS, and transgenic Helianthus annuus plants expressing a miR396resistant HaWRKY6 gene exhibited enhanced tolerance to HS [53]. 


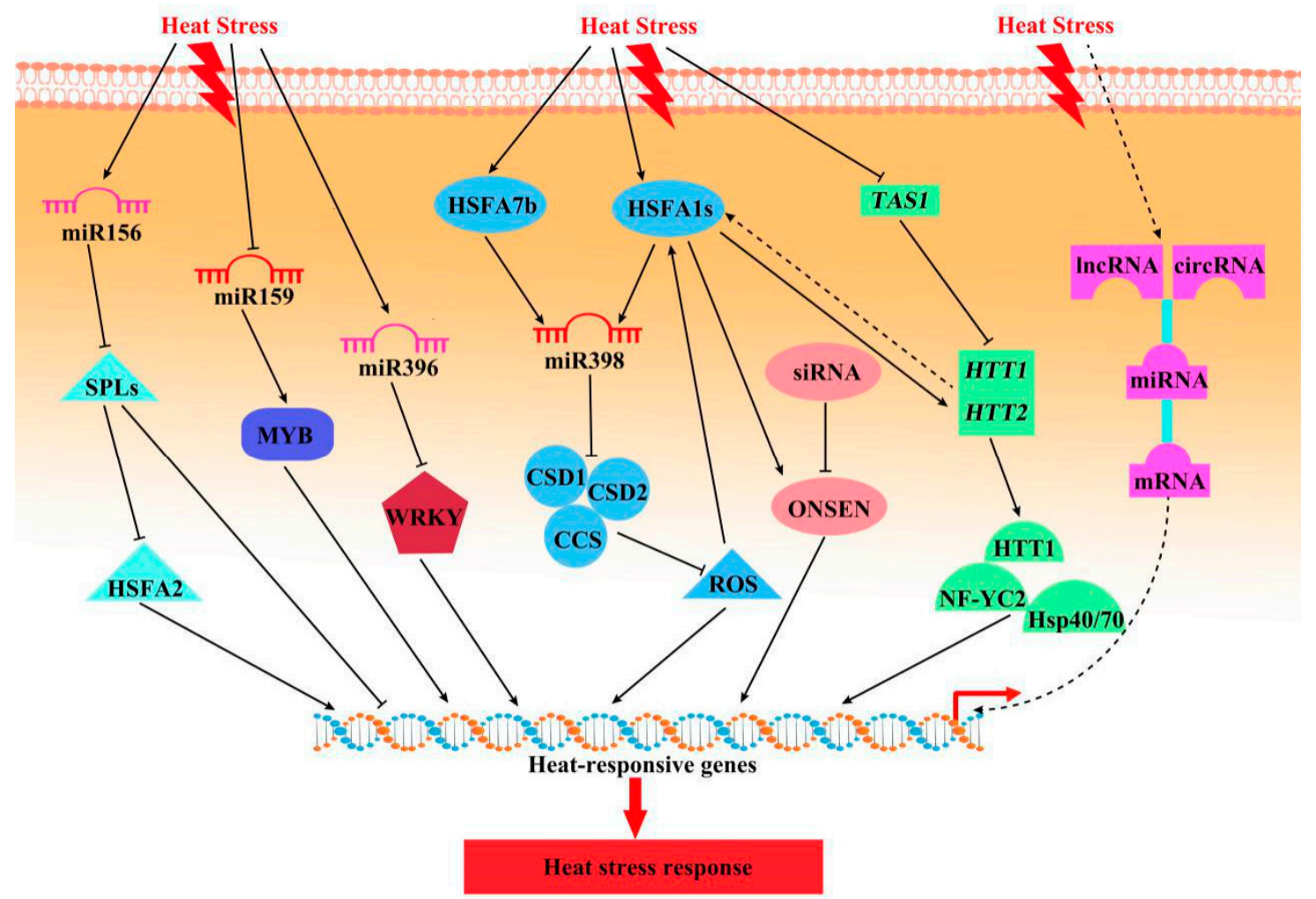

Figure 3. Roles of non-coding RNAs in the plant HS response. Dotted lines represent as yet unidentified factors in the corresponding pathways. Abbreviations: SPL, squamosa promoter-binding protein-like; HSF, heat shock transcription factor; CSD, copper/zinc superoxide dismutase; CCS, copper chaperone for superoxide dismutase; ROS, reactive oxygen species; TAS1, trans-acting siRNA precursor 1; HTT, heat-induced tas1 target; NF-YC2, nuclear factor Y, subunit C; lncRNA, long non-coding RNA; circRNA, circular RNA; siRNA, small interfering RNA; miRNA, microRNA; mRNA, messenger RNA.

Small interfering RNAs, approximately 21-24-nucleotide endogenous RNAs, are involved in plant responses to abiotic stresses. They are classified into trans-acting small interfering RNAs (ta-siRNAs, TAS), natural antisense transcript siRNAs (nat-siRNAs), and heterochromatic siRNAs [51,54]. In Arabidopsis, the copia-like retrotransposon ONSEN was activated in siRNA biogenesis mutants during HS, likely because ONSEN is a target of HSFA1 and HSFA2. In addition, new ONSEN insertions were detected in progeny after $\mathrm{HS}$, and conferred heat-responsiveness to genes near the new insertion sites, suggesting a role for ONSEN transposition in transgenerational HS memory [55]. ta-siRNAs are distinctive siRNAs generated by miRNA processing of a noncoding TAS precursor RNA. HEAT-INDUCED TAS1 TARGET1 (HTT1) and HTT2 are involved in thermotolerance and are targeted by TAS1 (trans-acting siRNA precursor 1)-derived siRNAs (Figure 3). Under HS, TAS1 negatively regulates HTT1 and HTT2 and reduces thermotolerance. In addition, HSFA1a also directly activates HTT1 and HTT2 by binding to their promoters, inducing thermotolerance [56]. In Brassica rapa, nat-siRNAs derived from cis-NATs were responsive to HS, suggesting that nat-siRNAs may play important roles in heat resistance [57].

lncRNAs and circRNAs function as competitive endogenous RNAs and are regulated by competition for binding to common miRNA response elements [58]. lncRNAs are diverse transcripts longer than $200 \mathrm{nt}$ and are vital in the plant HS response. The expression level of the lncRNA PsiLncRNA00268512 was dynamic in response to HS in P. simonii [59]. In addition, in B. rapa, competition between lncRNAs and protein-coding genes for binding to miR159a or miR172a regulates target genes or heat-responsive genes (e.g., HSPs, HSFs, and DREB2A) [60]. circRNAs are single-stranded RNAs in closed circular form and are involved in regulation of the plant response to HS. In Cucumis sativus, many miRNAs, with mRNAs, lncRNAs, and circRNAs, are associated with plant hor- 
mone signal transduction pathways in response to HS [58]. However, the lncRNA and circRNA responses to HS are unclear, particularly the lncRNA/circRNA-miRNA-mRNA coexpression network (Figure 3).

\subsection{Epigenetic Regulation in the Plant HS Response and Memory}

Epigenetics refers to the heritable changes in gene expression that occur without DNA sequence variations and are pivotal for the plant HS response [61,62]. The epigenetic regulatory system in response to heat involves DNA methylation, histone modification, chromatin remodeling (Figure 4), sRNAs, and lncRNAs, which alter the gene expression pattern and/or epigenetic memory of plants under HS [63,64].

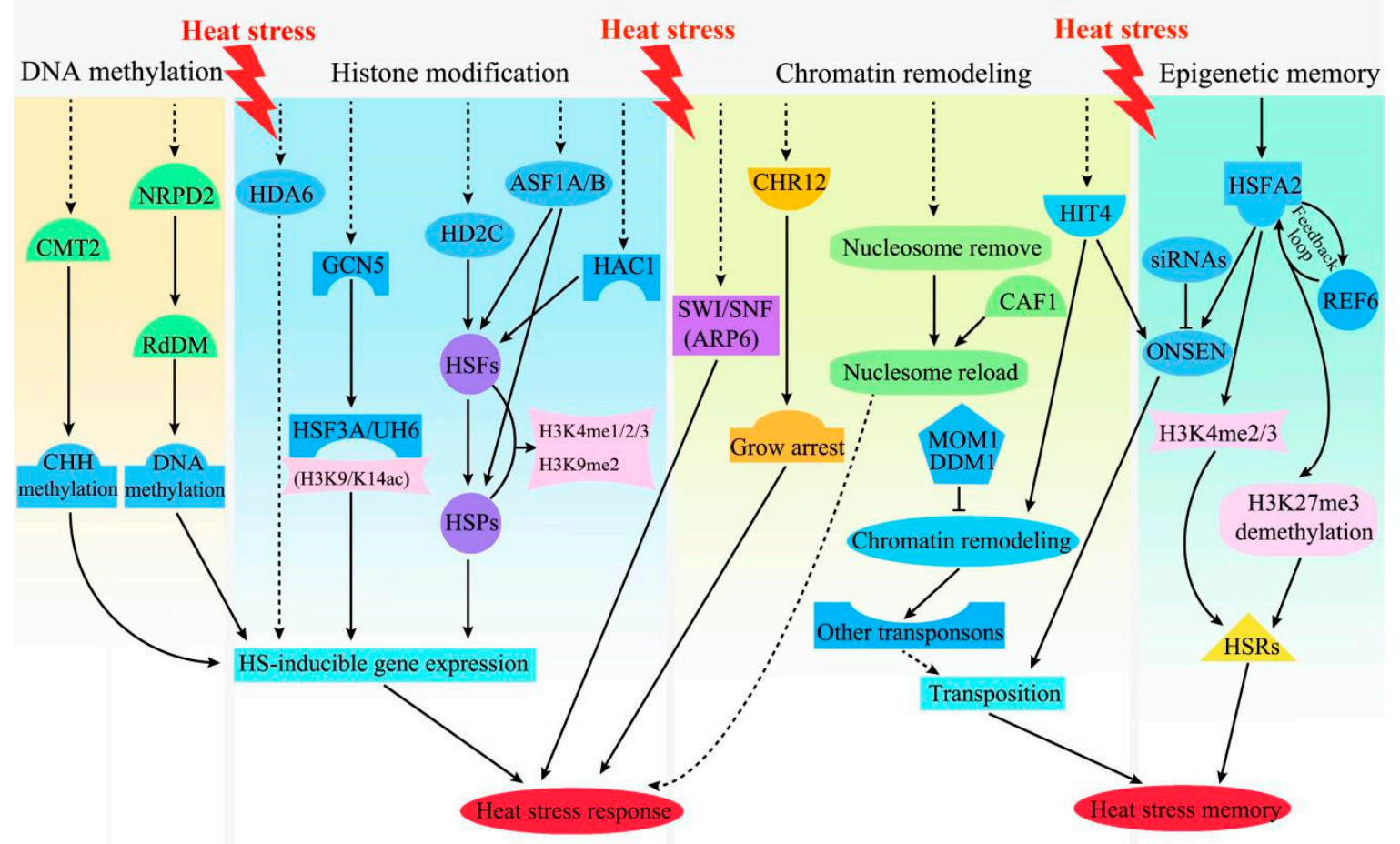

Figure 4. Epigenetic regulation of the plant response to HS, including DNA methylation, histone modification, chromatin remodeling, and epigenetic memory. Dotted lines represent as yet unidentified factors in the corresponding pathways. Abbreviations: CMT2, chromomethylase 2; NRPD2, nuclear RNA polymerase D2; RdDM, RNA-directed DNA methylation; HDA6, histone deacetylase 6; GCN5, general control nonderepressible 5; HD2C, histone deacetylase 2C; ASF1A/B, antisilencing function 1A/B; HAC1, histone acetyltransferase 1; SWI/SNF, SWItch/sucrose non-fermentable; ARP6, actin-related protein 6; CHR, chromatin remodeling; CAF1, chromatin assembly factor 1; MOM1, morpheus' molecule 1; DDM1, decrease in DNA methylation 1; HIT4, heat-intolerant 4; REF6, relative of early flowering 6; H3K4/9/27me, H3K4/9/27 methylation; H3K9/K14ac, H3K9/K14 acetylation; HSR, heat stress response.

\subsubsection{DNA Methylation}

DNA methylation involves the transfer of a methyl group $\left(\mathrm{CH}_{3}\right)$ to the cytosine position of DNA to form 5-methylcytosine, forming CG, CHG, and $\mathrm{CHH}$ (H represents $\mathrm{A}, \mathrm{T}$, or C) [65]. DNA methylation is involved in the regulation of genes implicated in the plant response to HS $[63,66,67]$. Upon exposure to HS, genome-wide methylation is increased significantly in Arabidopsis thaliana and Quercus suber under extreme heat $[68,69]$. In Brassica napus, the levels of DNA methylation increased more in a heat-sensitive than a heat-tolerant genotype under HS [70]. By contrast, decreased expression of S-ADENOSYLL-HOMOCYSTEINE HYDROLASE1 (SAHH1) and DNA methyltransferases under HS reduced genome-wide DNA methylation in a heat-sensitive compared to a heat-tolerant 
(HT) cotton line [71]. Comparison of the methylation of cotton anthers at different stages in heat-sensitive and HT lines suggests that global disruption of DNA methylation (especially $\mathrm{CHH}$ methylation) in the heat-sensitive line at high temperatures leads to male sterility [72] Interestingly, cold-acclimated B. rapa alters DNA methylation patterns to enhance its heat tolerance and maintain growth [67]. Therefore, global methylation is affected differently by heat among plant species and is linked to plant development.

Analysis of the heat tolerance of DNA methylation-deficient mutants revealed that the RNA-directed DNA methylation (RdDM) pathway is required for basal thermotolerance [66]. Arabidopsis plants deficient in DRM1/DRM2 (domains rearranged methyltransferase 1/2) and CMT3 (chromomethylase 3) are less sensitive to HS, but mutants in nrpd2 (nuclear RNA polymerase D 2), dcl3 (dicer-like 3), rdr2 (RNA-dependent RNA polymerase 2), and ago4 (argonaute 4), which are involved in the RdDM pathway, are hypersensitive to heat (Figure 4). Further studies on $n r p d 2$ mutants recovering from heat revealed that the misexpression of heat-dependent genes is correlated with defective epigenetic regulation of adjacent transposon remnants. For instance, in $n r p d 2$ mutants, transcriptional activity of the COPIA-like transposon At1g29475 was increased by heat but did not decrease during recovery. By contrast, the expression of auxin-responsive genes near the transposon was downregulated during recovery of $n r p d 2$ plants [66]. Similarly, the heat-responsive LTRcopia type retrotransposon ONSEN, which is enhanced in several RdDM pathways, confers heat-responsiveness to genes close to the new insertion site [55]. Moreover, the expression of Calmodulin-like 41 (CML41, At3g50770) is enhanced by HS and shows a reduced methylation level in the transposable element (TE) insertion close to the transcriptional start site [73]. Therefore, the RdDM pathway affects the transcription of genes near transposons or containing TEs by changing their DNA methylation status, which can improve plant basal thermotolerance. By contrast, plants deficient in CMT2, which is responsible for $\mathrm{CHH}$ methylation, have improved HS tolerance (Figure 4), suggesting that CMT2-dependent $\mathrm{CHH}$ methylation alleviates the plant response to HS [74].

\subsubsection{Histone Modification}

Histone octamers comprise two copies of $\mathrm{H} 2 \mathrm{~A}, \mathrm{H} 2 \mathrm{~B}, \mathrm{H} 3$, and H4, wrapped in $\approx 147 \mathrm{bp}$ DNA, forming the basic structural unit in nucleosome of chromatin. Histone acetylation and methylation mediate the plant HS response by repressing or activating gene expression. In Chlamydomonas reinhardtii, a high level of histone $\mathrm{H} 3 / 4$ acetylation (H3/4ac) and a low level of H3K4 methylation 1 (H3K4me1) were found in the promoter regions of active genes after HS [75]. By contrast, the level of acetylated histone $\mathrm{H} 3$ was decreased in the cork oak tree exposed to $45{ }^{\circ} \mathrm{C}$. Similarly, the levels of H3K9me2 and H3K4me3 are significantly reduced after prolonged HS in Arabidopsis [76]. Moreover, the H3K9me2 level of OsFIE1, which is related to rice seed development, is temperature-sensitive (moderate $\mathrm{HS}, 34^{\circ} \mathrm{C}$ ) and may regulate OsFIE1 expression for rice seed development [77]. Therefore, these two histone modifications are differently affected by heat among plant species.

Several epigenetic regulators-such as acetyltransferases, methyltransferases, deacetylases, and demethylases - mediate methylation and acetylation during the HS response [78]. These epigenetic regulators are recruited by heat response-associated recruiters (e.g., TFs, lncRNAs) to specific histones in chromatin to regulate gene expression [64,79]. A. thaliana plants deficient in acetyltransferase GCN5 exhibit serious defects in thermotolerance under HS, and GCN5 may positively regulate thermotolerance by facilitating H3K9/K14 acetylation in the promoter regions of HSFA3 and ULTRAVIOLET HYPERSENSITIVE6 (Figure 4) [80]. Histone deacetylase 6 (HDA6), an RPD3-type deacetylase, is implicated in repression of gene expression by RdDM [81]. hda6 mutants were hypersensitive to extreme heat, suggesting HDA6 is required for HS [82]. The transcript level of the histone deacetylase, HD2C, was increased in Arabidopsis subjected to heat treatment (Figure 4). An $h d 2 c$ mutant analysis showed that HD2C downregulates heat-activated genes, implicating HD2C in regulation of the plant HS response. Because HD2C interacts with HDA9, HDA6, and BRAHMA (BRM)-containing SWITCH/SUC NONFERMENTING chromatin remodeling 
complex, association analyses are warranted to uncover the mechanisms underlying their roles in the plant HS response [82-84]. In tomato, HSFB1 recruits histone acetyltransferase 1 (HAC1) to chromatin, suggesting that the interaction of HSFB1 with HAC1 regulates gene expression in response to prolonged HS [85]. The histone chaperones AtASF1A (ANTI-SILENCING FUNCTION 1) and AtASF1B are involved in transcriptional activation in response to HS [86]. AtASF1A/B proteins are recruited onto chromatin, which was correlated with nucleosome removal and RNA polymerase II accumulation at the promoter and coding regions of HSFs and HSPs (Figure 4). Moreover, AtASF1A/B mediates the removal of H3K56ac marks from HSRs (heat stress response genes). In addition, the histone variant H2A.Z plays an important role in the thermosensory response in Arabidopsis [87]. Furthermore, the H2A.Z nucleosome regulates the binding of PIF4 (PHYTOCHROME INTERACTING FACTOR 4) to the FT (FLOWERING LUCUS T) promoter, thus mediating thermosensory activation of flowering [88]. PIF4 as a central regulator alters plant morphology (e.g., hypocotyl elongation, petiole elongation) at high temperatures by binding to the promoters of YUC8 (YUCCA8), TAA1 (TRYPTOPHAN AMINOTRANSFERASE OF ARABIDOPSIS), CYP79B2 (CYTOCHROME P450, FAMILY 79, SUBFAMILY B, POLYPEPTIDE 2), and SAUR (SMALL AUXIN UP RNA) 19-24 [63]. Therefore, H2A.Z may participate in regulation of plant morphology at high temperatures. However, whether H2A.Z modulates plant morphological acclimation to higher temperatures (e.g., extreme HS) and binds to other heat-response genes requires further investigation.

\subsubsection{Chromatin Remodeling}

ATP-dependent chromatin remodeling complexes are involved in the plant response to HS [63]. The SWItch/sucrose non-fermentable (SWI/SNF) complex was first identified in Arabidopsis, and its key component ARP6 (SWI complex) is essential for temperature sensing. Under heat and drought stress, overexpression of the SNF2/Brahma-type chromatinremodeling gene CHR12 (CHROMATIN REMODELING) caused growth arrest of flower buds and primary stems of $A$. thaliana, whereas AtCHR12-knockout Arabidopsis plants showed reduced growth arrest relative to the wild-type plants (Figure 4) [89]. This indicates that CHR12 mediates temporary growth arrest of Arabidopsis under heat and drought stress. Additionally, upon resumption of a normal temperature, the $\mathrm{H} 3-\mathrm{H} 4$ chaperone CAF-1 (CHROMATIN ASSEMBLY FACTOR-1) participates in reloading of nucleosomes onto chromosomes in A. thaliana [76], indicating its importance in chromatin remodeling (Figure 4). In addition, HS relaxes the silencing of transposons by chromocenter decondensation mediated by HEAT-INTOLERANT 4 (HIT4), whereas most of these transposons are repressed rapidly by MORPHEUS' MOLECULE 1 (MOM1)- and DECREASE IN DNA METHYLATION 1 (DDM1)-mediated chromatin remodeling [90].

\subsubsection{Epigenetic Memory}

Epigenetic memory improves plant adaptation to various stress environments $[61,91$, 92]. Histone modification and HSFA2 are important for HS memory in A. thaliana. The level of $\mathrm{H} 3 \mathrm{~K} 4$ methylation $(\mathrm{H} 3 \mathrm{~K} 4 \mathrm{me} 2 / 3)$, which is associated with transcriptional memory, was higher for at least 2 days after a priming heat shock [93]. Accumulation of H3K4 methylation is important for HSR expression and transcriptional HS memory, and this modification depends on HSFA2 (Figure 4). HSFA2 and H3K27me3 demethylase RELATIVE OF EARLY FLOWERING 6 (REF6) display a positive feedback loop to transmit long-term epigenetic memory in A. thaliana (Figure 4) [94]. In wheat, the level of lysine-specific histone demethylase 1 (LSD1) was upregulated in the progeny of heat-primed plants compared to that of non-heat primed plants, implicating histone modification in the induction of transgenerational thermo-tolerance by heat priming. HS-induced transgenerational epigenetic memory or phenotypic changes can be maintained for at least three generations [95,96]. In addition, the ONSEN retrotransposon, as mentioned above, is transcriptionally activated in plants exposed to HS. Interestingly, ONSEN transposition occurs more frequently in the progeny 
of RdDM mutants subjected to HS (Figure 4), indicating that RdDM-mediated epigenetic modification prevents transgenerational propagation of retrotransposons in plants [55,97].

\section{Conclusions and Perspectives}

Over the last decade, the mechanisms of the plant response to HS have been investigated in model plants. Our understanding of the regulatory networks involved in the plant HS response is mainly derived from model plants, such as Arabidopsis, rice, and tomato; few studies focused on non-model plants such as some agricultural crops and forestry trees (woody plants). Some genes may have experienced functional divergence during evolution, and homologous genes in different plants may have evolved different functions. Therefore, further studies of non-model plants are needed to enhance the understanding of the gene regulation networks underlying the plant HS response. Fortunately, advancements in genome sequencing, bioinformatics, and genetic transformation are enabling non-model plant research. By contrast, global warming is increasing the frequency of heat waves. Compared with short-term HS used in laboratory studies, the duration of warming events is longer, resulting in crop yield reductions. Therefore, efforts should focus on the plant response to long-term or prolonged HS, including transgenerational and multigenerational HS. This will facilitate evaluation of plant responses to climatic conditions and contribute to our ability to help plants cope with the warmer weather expected in the future.

The HS response mechanism at the transcriptional level of model plants has been gradually outlined. By contrast, the functions and interactions of important epigenetic regulatory factors in the plant HS response are unclear. Moreover, previous studies of epigenetic modification in response to HS focused on methylation and acetylation, whereas works on other epigenetic modifications - such as phosphorylation, ubiquitination, and SUMOylation (Small Ubiquitin-like Modifier, SUMO)—are scarce. Moreover, most methylation studies involved DNA, and little is known of RNA methylation in response to HS. Recently developed technologies, e.g., ATAC-seq (assay for transposase-accessible chromatin sequencing), histone modification, RNA modification $(\mathrm{m} 6 \mathrm{~A} / \mathrm{m} 1 \mathrm{~A} / \mathrm{m} 5 \mathrm{C})$, and single-cell RNAseq, will enhance research on epigenetic modifications under HS.

Another important question in the plant HS response is how heat is sensed. Identification of plant thermosensors may provide the missing link between the heat cue and the subsequent response [98]. Thermosensors must be activated directly by heat and require no upstream signaling components, excluding indirectly affected putative thermosensors. Heat affects DNA, RNA, protein, and lipids, and thus plant thermosensors may be composed of any one or a combination of these molecules. A prion-like domain in Arabidopsis rapidly shifts EARLY FLOWERING 3 (ELF3) between active and inactive states via phase transition [99]. Phase transition underlies the formation of biomolecular condensates in response to stimuli (e.g., temperature changes) [100]. Therefore, more research is needed to provide insight into the role of phase transition in the plant response to HS.

Author Contributions: B.J. and J.Z. conceived and designed this research; J.Z., Z.L., and B.J. wrote the manuscript. J.Z., Z.L., L.W., and B.J. reviewed and updated the manuscript. All authors have read and agreed to the published version of the manuscript.

Funding: This research received no external funding.

Conflicts of Interest: The authors declare no conflict of interest.

\section{References}

1. Lippmann, R.; Babben, S.; Menger, A.; Delker, C.; Quint, M. Development of wild and cultivated plants under global warming conditions. Curr. Biol. 2019, 29, R1326-R1338. [CrossRef] [PubMed]

2. Hedhly, A.; Hormaza, J.; Herrero, M. Global warming and sexual plant reproduction. Trends Plant Sci. 2009, 14, 30-36. [CrossRef] [PubMed]

3. Liu, J.; Zhang, R.; Xu, X.; Fowler, J.C.; Miller, T.E.X.; Dong, T. Effect of summer warming on growth, photosynthesis and water status in female and male Populus cathayana: Implications for sex-specific drought and heat tolerances. Tree Physiol. 2020, 40, 1178-1191. [CrossRef] [PubMed] 
4. Akter, N.; Islam, M.R. Heat stress effects and management in wheat. A review. Agron. Sustain. Dev. 2017, 37, 37. [CrossRef]

5. Xalxo, R.; Yadu, B.; Chandra, J.; Chandrakar, V.; Keshavkant, S. Alteration in Carbohydrate Metabolism Modulates Thermotolerance of Plant under Heat Stress. In Heat Stress Tolerance in Plants: Physiological, Molecular and Genetic Perspectives, 1st ed.; Wani, S.H., Kumar, V., Eds.; John Wiley \& Sons Ltd.: Hoboken, NJ, USA, 2020; pp. 77-115. [CrossRef]

6. Hasanuzzaman, M.; Nahar, K.; Alam, M.M.; Roychowdhury, R.; Fujita, M. Physiological, biochemical, and molecular mechanisms of heat stress tolerance in plants. Int. J. Mol. Sci. 2013, 14, 9643-9684. [CrossRef] [PubMed]

7. Hu, S.; Ding, Y.; Zhu, C. Sensitivity and responses of chloroplasts to heat stress in plants. Front. Plant Sci. 2020, 11, 375. [CrossRef] [PubMed]

8. Renata Szymańska Lesak, I.; Orzechowska, A.; Kruk, J. Physiological and biochemical responses to high light and temperature stress in plants. Environ. Exp. Bot. 2017, 139, 165-177.

9. Song, Y.; Chen, Q.; Ci, D.; Shao, X.; Zhang, D. Effects of high temperature on photosynthesis and related gene expression in poplar. BMC Plant Biol. 2014, 14, 111. [CrossRef]

10. Perdomo, J.A.; Capó-Bauçà, S.; Carmo-Silva, E.; Galmés, J. Rubisco and rubisco activase play an important role in the biochemical limitations of photosynthesis in rice, wheat, and maize under high temperature and water deficit. Front. Plant Sci. 2017, 8, 490. [CrossRef]

11. Bita, C.E.; Gerats, T. Plant tolerance to high temperature in a changing environment: Scientific fundamentals and production of heat stress-tolerant crops. Front. Plant Sci. 2013, 4, 273. [CrossRef]

12. Dhanda, S.S.; Munjal, R. Heat tolerance in relation to acquired thermotolerance for membrane lipids in bread wheat. Field Crops Res. 2012, 135, 30-37. [CrossRef]

13. Abdul-Razack, M.; Tarpley, L. Impact of high nighttime temperature on respiration, membrane stability, antioxidant capacity, and yield of rice plants. Crop. Sci. 2009, 49, 313-322.

14. Nosaka, Y.; Nosaka, A.Y. Generation and detection of reactive oxygen species in photocatalysis. Chem. Rev. 2017, 117, 11302-11336. [CrossRef] [PubMed]

15. Wang, X.; Xin, C.; Cai, j.; Zhou, Q.; Dai, T.; Cao, W.; Jiang, D. Heat priming induces trans-generational tolerance to high temperature stress in wheat. Front. Plant Sci. 2016, 7, 501. [CrossRef] [PubMed]

16. Djanaguiraman, M.; Prasad, P.V.V.; Seppanen, M. Selenium protects sorghum leaves from oxidative damage under high temperature stress by enhancing antioxidant defense system. Plant Physiol. Biochem. 2010, 48, 999-1007. [CrossRef]

17. Jespersen, D. Heat shock induced stress tolerance in plants: Physiological, biochemical, and molecular mechanisms of acquired tolerance. In Priming-Mediated Stress and Cross-Stress Tolerance in Crop Plants, 1st ed.; Hossain, M.A., Liu, F., David, J., Burritt, D., Eds.; Academic Press Elsevier Inc.: London, UK, 2020; pp. 161-174. [CrossRef]

18. Wang, L.; Ma, K.B.; Lu, Z.G.; Ren, S.X.; Jiang, H.R.; Cui, J.W.; Chen, G.; Teng, N.J.; Lam, H.M.; Jin, B. Differential physiological, transcriptomic and metabolomic responses of Arabidopsis leaves under prolonged warming and heat shock. BMC Plant Biol. 2020, 20, 86. [CrossRef]

19. Zhang, X.; Cai, J.; Wollenweber, B.; Liu, F.; Dai, T.; Cao, W.; Jiang, D. Multiple heat and drought events affect grain yield and accumulations of high molecular weight glutenin subunits and glutenin macropolymers in wheat. J. Cereal Sci. 2013, 57, 134-140. [CrossRef]

20. Ohama, N.; Sato, H.; Shinozaki, K.; Yamaguchi-Shinozaki, K. Transcriptional regulatory network of plant heat stress response. Trends Plant Sci. 2017, 22, 53-65. [CrossRef]

21. Ren, S.; Ma, K.; Lu, Z.; Chen, G.; Cui, J.; Tong, P.; Wang, L.; Teng, N.; Jin, B. Transcriptomic andmetabolomic analysis of the heat-Stress response of Populus tomentosa Carr. Forests 2019, 10, 383. [CrossRef]

22. Scharf, K.D.; Berberich, T.; Ebersberger, I.; Nover, L. The plant heat stress transcription factor (Hsf) family: Structure, function and evolution. Biochim. Biophys. Acta 2012, 1819, 104-119. [CrossRef]

23. Hahn, A.; Bublak, D.; Schleiff, E.; Scharf, K.D. Crosstalk between Hsp90 and Hsp70 chaperones and heat stress transcription factors in tomato. Plant Cell 2011, 23, 741-755. [CrossRef] [PubMed]

24. Li, M.; Berendzen, K.W.; Schoffl, F. Promoter specificity and interactions between early and late Arabidopsis heat hock factors Plant Mol. Biol. 2010, 73, 559-567. [CrossRef] [PubMed]

25. Li, X.; Wang, X.; Cai, Y.; Wu, J.; Mo, B.; Yu, E. Arabidopsis heat stress transcription factors A2 (HSFA2) and A3 (HSFA3) function in the same heat regulation pathway. Acta Physiol. Plantarum. 2017, 39, 1-9. [CrossRef]

26. Sato, H.; Mizoi, J.; Tanaka, H.; Maruyama, K.; Qin, F.; Osakabe, Y.; Morimoto, K.; Ohori, T.; Kusakabe, K.; Nagata, M.; et al. Arabidopsis DPB3-1, a DREB2A interactor, specifically enhances heat stress-induced gene expression by forming a heat stress-specific transcriptional complex with NF-Y subunits. Plant Cell 2014, 26, 4954-4973. [CrossRef] [PubMed]

27. Qu, A.L.; Ding, Y.F.; Jiang, Q.; Zhu, C. Molecular mechanisms of the plant heat stress response. Biochem. Biophys. Res. Commun. 2013, 432, 203-207. [CrossRef]

28. Ding, Y.L.; Shi, Y.T.; Yang, S.H. Molecular regulation of plant responses to environmental temperatures. Mol. Plant 2020, 13, 544-564. [CrossRef]

29. Zhuang, L.; Cao, W.; Wang, J.; Yu, J.; Yang, Z.; Huang, B. Characterization and functional analysis of FaHsfC1b from Festuca arundinacea conferring heat tolerance in Arabidopsis. Int. J. Mol. Sci. 2018, 19, 2702. [CrossRef]

30. Xue, G.P.; Sadat, S.; Drenth, J.; Mcintyre, C.L. The heat shock factor family from Triticum aestivum in response to heat and other major abiotic stresses and their role in regulation of heat shock protein genes. J. Exp. Bot. 2014, 65, 539-557. [CrossRef] 
31. Huang, X.Y.; Tao, P.; Li, B.Y.; Wang, W.H.; Yue, Z.C.; Lei, J.L.; Zhong, X.M. Genome-wide identification, classification, and analysis of heat shock transcription factor family in Chinese cabbage (Brassica rapa pekinensis). Genet. Mol. Res. 2015, 14, $2189-2204$. [CrossRef]

32. Li, P.S.; Yu, T.F.; He, G.H.; Chen, M.; Zhou, Y.B.; Chai, S.C.; Xu, Z.S.; Ma, Y.Z. Genome-wide analysis of the Hsf family in soybean and functional identification of GmHsf-34 involvement in drought and heat stresses. BMC Genom. 2014, 15, 1009. [CrossRef]

33. Suzuki, N.; Sejima, H.; Tam, R.; Schlauch, K.; Mittler, R. Identification of the MBF1 heat-response regulon of Arabidopsis thaliana. Plant J. 2011, 66, 844-851. [CrossRef] [PubMed]

34. Guan, Q.; Yue, X.; Zeng, H.; Zhu, J. The protein phosphatase rcf2 and its interacting partner nac019 are critical for heat stress-responsive gene regulation and thermotolerance in Arabidopsis. Plant Cell 2014, 26, 438-453. [CrossRef] [PubMed]

35. Liu, X.H.; Lyu, Y.S.; Yang, W.; Yang, Z.T.; Lu, S.J.; Liu, J.X. A membrane-associated NAC transcription factor OsNTL3 is involved in thermotolerance in rice. Plant Biotechnol. J. 2019, 18, 1317-1329. [CrossRef] [PubMed]

36. Guo, W.; Zhang, J.; Zhang, N.; Xin, M.; Peng, H.; Hu, Z.; Ni, Z.; Du, J. The Wheat NAC transcription factor TaNAC2L is regulated at the transcriptional and post-translational levels and promotes heat stress tolerance in transgenic Arabidopsis. PLoS ONE 2015, 10, e0135667. [CrossRef] [PubMed]

37. Fang, Y.; Liao, K.; Du, H.; Xu, Y.; Song, H.; Li, X.; Xiong, L. A stress-responsive NAC transcription factor SNAC3 confers heat and drought tolerance through modulation of reactive oxygen species in rice. J. Exp. Bot. 2015, 66, 6803-6817. [CrossRef]

38. Shahnejat-Bushehri, S.; Mueller-Roeber, B.; Balazadeh, S. Arabidopsis NAC transcription factor JUNGBRUNNEN1 affects thermomemory-associated genes and enhances heat stress tolerance in primed and unprimed conditions. Plant Signal. Behav. 2012, 7, 1518-1521. [CrossRef]

39. Li, S.; Zhou, X.; Chen, L.; Huang, W.; Yu, D. Functional characterization of Arabidopsis thaliana wrky39 in heat stress. Mol. Cells 2010, 29, 475. [CrossRef]

40. Li, S.; Fu, Q.; Chen, L.; Huang, W.; Yu, D. Arabidopsis thaliana WRKY25, WRKY26, and WRKY33 coordinate induction of plant thermotolerance. Planta 2011, 233, 1237-1252. [CrossRef]

41. Wu, X.; Shiroto, Y.; Kishitani, S.; Ito, Y.; Toriyama, K. Enhanced heat and drought tolerance in transgenic rice seedlings overexpressing oswrky11 under the control of hsp101 promoter. Plant Cell Rep. 2009, 28, 21-30. [CrossRef]

42. Lai, Y.S.; Renna, L.; Yarema, J.; Ruberti, C.; He, S.Y.; Brandizzi, F. Salicylic acid-independent role of NPR1 is required for protection from proteotoxic stress in the plant endoplasmic reticulum. Proc. Natl. Acad. Sci. USA 2018, 115, E5203-E5212. [CrossRef]

43. Kataoka, R.; Takahashi, M.; Suzuki, N. Coordination between bZIP28 and HSFA2 in the regulation of heat response signals in Arabidopsis. Plant Signal. Behav. 2017, 12, e1376159. [CrossRef] [PubMed]

44. Wu, Z.; Liang, J.; Wang, C.; Zhao, X.; Zhong, X.; Cao, X.; Li, G.; He, J.; Yi, M. Overexpression of lily HsfA3s in Arabidopsis confers increased thermotolerance and salt sensitivity via alterations in proline catabolism. J. Exp. Bot. 2018, 69, 2005-2021. [CrossRef] [PubMed]

45. Liao, C.; Zheng, Y.; Guo, Y. Myb30 transcription factor regulates oxidative and heat stress responses through ANNEXIN-mediated cytosolic calcium signaling in Arabidopsis. New Phytol. 2017, 216, 163-177. [CrossRef] [PubMed]

46. El-Kereamy, A.; Bi, Y.M.; Ranathunge, K.; Beatty, P.H.; Good, A.G.; Rothstein, S.J. The rice R2R3-MYB transcription factor OsMYB55 is involved in the tolerance to high temperature and modulates amino acid metabolism. PLoS ONE 2012, 7, e52030. [CrossRef] [PubMed]

47. Matsui, A.; Nguyen, A.H.; Nakaminami, K.; Seki, M. Arabidopsis non-coding RNA regulation in abiotic stress responses. Int. J. Mol. Sci. 2013, 14, 22642-22654. [CrossRef] [PubMed]

48. Rogers, K.; Chen, X. Biogenesis, turnover and mode of action of plant microRNAs. Plant Cell 2013, 25, 2383-2399. [CrossRef] [PubMed]

49. Stief, A.; Altmann, S.; Hoffmann, K.; Pant, B.D.; Scheible, W.; Bäurle, I. Arabidopsis miR156 regulates tolerance to recurring environmental stress through SPL transcription factors. Plant Cell 2014, 26, 1792-1807. [CrossRef]

50. Guan, Q.; Lu, X.; Zeng, H.; Zhang, Y.; Zhu, J. Heat stress induction of miR398 triggers a regulatory loop that is critical for thermotolerance in Arabidopsis. Plant J. 2013, 74, 840-851. [CrossRef]

51. Zhao, J.; He, Q.; Chen, G.; Wang, L.; Jin, B. Regulation of non-coding RNAs in heat stress responses of plants. Front. Plant Sci. 2016, 7, 1213. [CrossRef]

52. Wang, Y.; Sun, F.; Cao, H.; Peng, H.R.; Ni, Z.F.; Sun, Q.X.; Yao, Y.Y. TamiR159 directed wheat TaGAMYB cleavage and its involvement in anther development and heat response. PLoS ONE 2012, 7, e48445. [CrossRef]

53. Giacomelli, J.I.; Weigel, D.; Chan, R.L.; Manavella, P.A. Role of recently evolved mirna regulation of sunflower hawrky6 in response to temperature damage. New Phytol. 2012, 195, 766-773. [CrossRef] [PubMed]

54. Axtell, M.J. Classification and comparison of small RNAs from plants. Annu. Rev. Plant Biol. 2013, 64, 137-159. [CrossRef] [PubMed]

55. Ito, H.; Gaubert, H.; Bucher, E.; Mirouze, M.; Vaillant, I.; Paszkowski, J. An siRNA pathway prevents transgenerational retrotransposition in plants subjected to stress. Nature 2011, 472, 115-119. [CrossRef] [PubMed]

56. Li, S.X.; Liu, J.X.; Liu, Z.Y.; Li, X.R.; Wu, F.J.; He, Y.K. Heatinduced tas1 target1 mediates thermotolerance via heat stress transcription factor A1a-directed pathways in Arabidopsis. Plant Cell 2014, 26, 1764-1780. [CrossRef] [PubMed]

57. Yu, X.; Yang, J.; Li, X.; Liu, X.; Sun, C.; Wu, F.; He, Y.K. Global analysis of cisnatural antisense transcripts and their heat-responsive nat-siRNAs in Brassica rapa. BMC Plant Biol. 2013, 13, 208. [CrossRef] [PubMed] 
58. He, X.; Guo, S.; Wang, Y.; Wang, L.; Shu, S.; Sun, J. Systematic identification and analysis of heat-stress-responsive lncRNAs, circRNAs and miRNAs with associated co-expression and ceRNA networks in cucumber (Cucumis sativus L.). Physiol. Plant. 2020, 168, 736-754. [CrossRef] [PubMed]

59. Song, Y.; Ci, D.; Tian, M.; Zhang, D.Q. Stable methylation of a noncoding RNA gene regulates gene expression in response to abiotic stress in Populus simonii. J. Exp. Bot. 2015, 67, 1477-1492. [CrossRef] [PubMed]

60. Wang, A.; Hu, J.; Gao, C.; Chen, G.; Wang, B.; Lin, C.; Song, L.; Ding, Y.; Zhou, G. Genome-wide analysis of long non-coding RNAs unveils the regulatory roles in the heat tolerance of Chinese cabbage (Brassica rapa ssp.chinensis). Sci. Rep. 2019, 9, 5002. [CrossRef] [PubMed]

61. Kinoshita, T.; Seki, M. Epigenetic memory for stress response and adaptation in plants. Plant Cell Physiol. 2014, 55, 1859-1863. [CrossRef] [PubMed]

62. McCormick, S. Remembrance of stresses past: Heat shock factors and histone hypermethylation are key. Plant J. 2018, 95, 399-400. [CrossRef]

63. Liu, J.; Feng, L.; Li, J.; He, Z. Genetic and epigenetic control of plant heat responses. Front. Plant Sci. 2015, 6, 267. [CrossRef] [PubMed]

64. Ueda, M.; Seki, M. Histone Modifications form epigenetic regulatory networks to regulate abiotic stress response. Plant Physiol. 2020, 182, 15-26. [CrossRef] [PubMed]

65. Cokus, S.J.; Feng, S.; Zhang, X.; Chen, Z.; Merriman, B.; Haudenschild, C.D.; Pradhan, S.; Nelson, S.F.; Pellegrini, M.; Jacobsen, S.E. Shotgun bisulphite sequencing of the Arabidopsis genome reveals DNA methylation patterning. Nature 2008, 452, 215-219. [CrossRef] [PubMed]

66. Popova, O.V.; Dinh, H.Q.; Aufsatz, W.; Jonak, C. The RdDM pathway is required for basal heat tolerance in Arabidopsis. Mol. Plant 2013, 6, 396-410. [CrossRef] [PubMed]

67. Liu, T.; Li, Y.; Duan, W.; Huang, F.; Hou, X. Cold acclimation alters DNA methylation patterns and confers tolerance to heat and increases growth rate in Brassica rapa. J. Exp. Bot. 2017, 68, 1213-1224. [CrossRef] [PubMed]

68. Boyko, A.; Blevins, T.; Yao, Y.; Golubov, A.; Bilichak, A.; Ilnytskyy, Y.; Hollunder, J.; Meins, F., Jr.; Kovalchuk, I. Transgenerational adaptation of Arabidopsis to stress requires DNA methylation and the function of Dicer-like proteins. PLoS ONE 2010, 5, e9514. [CrossRef]

69. Correia, B.; Valledor, L.; Meijon, M.; Rodriguez, J.L.; Dias, M.C.; Santos, C.; Cañal, M.J.; Rodriguez, R.; Pinto, G. Is the interplay between epigenetic markers related to the acclimation of cork oak plants to high temperatures? PLoS ONE 2013, 8, e53543. [CrossRef]

70. Gao, G.; Li, J.; Li, H.; Li, F.; Xu, K.; Yan, G.; Chen, B.; Qiao, J.; Wu, X. Comparison of the heat stress induced variations in DNA methylation between heat-tolerant and heat-sensitive rapeseed seedlings. Breed. Sci. 2014, 64, 125-133. [CrossRef]

71. Min, L.; Li, Y.; Hu, Q.; Zhu, L.; Gao, W.; Wu, Y.; Ding, Y.; Liu, S.; Yang, X.; Zhang, X. Sugar and auxin signaling pathways respond to high-temperature stress during anther development as revealed by transcript profiling analysis in cotton. Plant Physiol. 2014, 164, 1293-1308. [CrossRef]

72. Ma, Y.; Min, L.; Wang, M.; Wang, C.; Zhao, Y.; Li, Y.; Fang, Q.; Wu, Y.; Xie, S.; Ding, Y.; et al. Disrupted genome methylation in response to high temperature has distinct affects on microspore abortion and anther indehiscence. Plant Cell 2018, 30, 1387-1403. [CrossRef]

73. Naydenov, M.; Baev, V.; Apostolova, E.; Gospodinova, N.; Sablok, G.; Gozmanova, M.; Yahubyan, G. High-temperature effect on genes engaged in DNA methylation and affected by DNA methylation in Arabidopsis. Plant Physiol. Biochem. 2015, 87, 102-108. [CrossRef] [PubMed]

74. Shen, X.; De Jonge, J.; Forsberg, S.K.; Pettersson, M.E.; Sheng, Z.; Hennig, L.; Carlborg, Ö. Natural CMT2 variation is associated with genome-wide methylation changes and temperature seasonality. PLoS Genet. 2014, 10, e1004842. [CrossRef]

75. Strenkert, D.; Schmollinger, S.; Sommer, F.; Schulz-Raffelt, M.; Schroda, M. Transcription factor-dependent chromatin remodeling at heat shock and copper-responsive promoters in Chlamydomonas reinhardtii. Plant Cell 2011, 23, 2285-2301. [CrossRef] [PubMed]

76. Pecinka, A.; Dinh, H.Q.; Baubec, T.; Rosa, M.; Lettner, N.; Mittelsten Scheid, O. Epigenetic regulation of repetitive elements is attenuated by prolonged heat stress in Arabidopsis. Plant Cell 2010, 22, 3118-3129. [CrossRef] [PubMed]

77. Folsom, J.J.; Begcy, K.; Hao, X.; Wang, D.; Walia, H. Rice fertilization-independent endosperm1 regulates seed size under heat stress by controlling early endosperm development. Plant Physiol. 2014, 165, 238-248. [CrossRef] [PubMed]

78. Xu, Y.; Zhang, S.; Lin, S.; Guo, Y.; Deng, W.; Zhang, Y.; Xue, Y. WERAM: A database of writers, erasers and readers of histone acetylation and methylation in eukaryotes. Nucleic Acids Res. 2017, 45, D264-D270. [PubMed]

79. Deng, X.; Qiu, Q.; He, K.; Cao, X. The seekers: How epigenetic modifying enzymes find their hidden genomic targets in Arabidopsis. Curr. Opin. Plant Biol. 2018, 45, 75-81. [CrossRef] [PubMed]

80. Hu, Z.; Song, N.; Zheng, M.; Liu, X.; Liu, Z.; Xing, J.; Ma, J.; Guo, W.; Yao, Y.; Peng, H.; et al. Histone acetyltransferase GCN5 is essential for heat stress-responsive gene activation and thermotolerance in Arabidopsis. Plant J. 2015, 84, 1178-1191. [CrossRef]

81. Earley, K.W.; Pontvianne, F.; Wierzbicki, A.T.; Blevins, T.; Tucker, S.; Costa-Nunes, P.; Pontes, O.; Pikaard, C.S. Mechanisms of HDA6-mediated rRNA gene silencing: Suppression of intergenic Pol II transcription and differential effects on maintenance versus siRNA-directed cytosine methylation. Genes Dev. 2010, 24, 1119-1132. [CrossRef] 
82. Buszewicz, D.; Archacki, R.; Palusiński, A.; Kotliński, M.; Fogtman, A.; Iwanicka-Nowicka, R.; Sosnowska, K.; Kuciński, J.; Pupel, P.; Olędzki, J.; et al. HD2C histone deacetylase and a SWI/SNF chromatin remodelling complex interact and both are involved in mediating the heat stress response in Arabidopsis. Plant Cell Environ. 2016, 39, 2108-2122. [CrossRef]

83. Park, J.; Lim, C.J.; Shen, M.; Park, H.J.; Cha, J.Y.; Iniesto, E.; Rubio, V.; Mengiste, T.; Zhu, J.K.; Bressan, R.A.; et al. Epigenetic switch from repressive to permissive chromatin in response to cold stress. Proc. Natl. Acad. Sci. USA 2018, 115, E5400-E5409. [CrossRef] [PubMed]

84. Park, H.J.; Baek, D.; Cha, J.Y.; Liao, X.; Kang, S.H.; McClung, C.R.; Lee, S.Y.; Yun, D.J.; Kim, W.Y. HOS15 interacts with the histone deacetylase HDA9 and the evening complex to epigenetically regulate the floral activator GIGANTEA. Plant Cell 2019, 31, 37-51. [CrossRef] [PubMed]

85. Bharti, K.; Von Koskull-Döring, P.; Bharti, S.; Kumar, P.; Tintschl-Körbitzer, A.; Treuter, E.; Nover, L. Tomato heat stress transcription factor HsfB1 represents a novel type of general transcription coactivator with a histone-like motif interacting with the plant CREB binding protein ortholog HAC1. Plant Cell 2004, 16, 1521-1535. [CrossRef] [PubMed]

86. Weng, M.; Yang, Y.; Feng, H.; Pan, Z.; Shen, W.H.; Zhu, Y.; Dong, A. Histone chaperone ASF1 is involved in gene transcription activation in response to heat stress in Arabidopsis thaliana. Plant Cell Environ. 2014, 37, 2128-2138. [CrossRef] [PubMed]

87. Kumar, S.V.; Wigge, P.A. H2A.Z-containing nucleosomes mediate the thermosensory response in Arabidopsis. Cell 2010, 140, 136-147. [CrossRef] [PubMed]

88. Kumar, S.V.; Lucyshyn, D.; Jaeger, K.E.; Alos, E.; Alvey, E.; Harberd, N.P.; Wigge, P.A. Transcription factor PIF4 controls the thermosensory activation of flowering. Nature 2012, 484, 242-245. [CrossRef] [PubMed]

89. Mlynarova, L.; Nap, J.P.; Bisseling, T. The SWI/SNF chromatin-remodeling gene AtCHR12 mediates temporary growth arrest in Arabidopsis thaliana upon perceiving environmental stress. Plant J. 2007, 51, 874-885. [CrossRef]

90. Iwasaki, M.; Paszkowski, J. Identification of genes preventing transgenerational transmission of stress induced epigenetic states Proc. Natl. Acad. Sci. USA 2014, 111, 8547-8552. [CrossRef]

91. Crisp, P.A.; Ganguly, D.; Eichten, S.R.; Borevitz, J.O.; Pogson, B.J. Reconsidering plant memory: Intersections between stress recovery, RNA turnover, and epigenetics. Sci. Adv. 2016, 2, e1501340. [CrossRef]

92. He, Y.; Li, Z. Epigenetic Environmental memories in plants: Establishment, maintenance, and reprogramming. Trends Genet. 2018, 34, 856-866. [CrossRef]

93. Lämke, J.; Brzezinka, K.; Altmann, S.; Bäurle, I. A hit-and-run heat shock factor governs sustained histone methylation and transcriptional stress memory. EMBO J. 2016, 35, 162-175. [CrossRef] [PubMed]

94. Liu, J.; Feng, L.; Gu, X.; Deng, X.; Qiu, Q.; Li, Q.; Zhang, Y.; Wang, M.; Deng, Y.; Wang, E.; et al. An H3K27me3 demethylase-HSFA2 regulatory loop orchestrates transgenerational thermomemory in Arabidopsis. Cell Res. 2019, 29, 379-390. [CrossRef] [PubMed]

95. Suter, L.; Widmer, A. Phenotypic effects of salt and heat stress over three generations in Arabidopsis thaliana. PLoS ONE 2013, 8 , e80819. [CrossRef] [PubMed]

96. Zhong, S.H.; Liu, J.Z.; Jin, H.; Lin, L.; Li, Q.; Chen, Y.; Yuan, Y.X.; Wang, Z.Y.; Huang, H.; Qi, Y.J.; et al. Warm temperatures induce transgenerational epigenetic release of RNA silencing by inhibiting siRNA biogenesis in Arabidopsis. Proc. Natl. Acad. Sci. USA 2013, 110, 9171-9176. [CrossRef] [PubMed]

97. Ito, H.; Yoshida, T.; Tsukahara, S.; Kawabe, A. Evolution of the ONSEN retrotransposon family activated upon heat stress in Brassicaceae. Gene 2013, 518, 256-261. [CrossRef] [PubMed]

98. Vu, L.D.; Gevaert, K.; De Smet, I. Feeling the heat: Searching for plant thermosensors. Trends Plant Sci. 2019, 24, 210-219. [CrossRef] [PubMed]

99. Jung, J.H.; Barbosa, A.D.; Hutin, S.; Kumita, J.R.; Gao, M.; Derwort, D.; Silva, C.S.; Lai, X.; Pierre, E.; Geng, F.; et al. A prion-like domain in ELF3 functions as a thermosensor in Arabidopsis. Nature 2020, 585, 256-260. [CrossRef]

100. Yoo, H.; Triandafillou, C.; Drummond, D.A. Cellular sensing by phase separation: Using the process, not just the products. J. Biol. Chem. 2019, 294, 7151-7159. [CrossRef] 